walkway of 1,200 students because their school is embraced by this public space. Once identified and brought in the authorities for this case study, the people's involvement (the students) pursued a safe community that leads healthy lives within their surrounding. The government accountability represents central and local administration. In 2010 central government issued to the local borough officials the technical guidelines and the monetary quote for restoring the sidewalk, but local officials disregarded them. In 2011, we obtained the funds at the CDMX Legislative Assembly, but the public work (2012-2013) resulted in a poor executed pedestrian infrastructure that remains unsafe so far.

Conclusions Central and local governments are ultimately accountable to their people for the health consequences of their actions. People should encourage the potential for producing and promoting healthy public spaces on the recognition of a fundamental human right and sound social investment.

\section{Child and Traffic Safety}

\section{Parallel Tue 3.2}

\section{ADVOCATING FOR THE IMPLEMENTATION OF GRADUATED DRIVER LICENSING IN THE UK}

Sarah J Jones. Public Health Wales

\subsection{6/injuryprev-2016-042156.327}

Background Although crash rates in the UK are some of the lowest in the world and are at their lowest levels ever, improvements are still possible and necessary. Analysis of crash data has shown that young drivers, aged 17 to 19 years, have crash rates that are disproportionately high when considered against the numbers of licence holders and size of the population of this age group.

Description of the problem Young drivers hold only around 2\% of driving licences, but are involved in $10-16 \%$ of crashes, casualties and fatalities. Review of the evidence has shown that Graduated Driver Licensing (GDL) has successfully reduced crashes in other parts of the world, but it is not currently used in the UK. This paper discusses efforts to advocate for the implementation of GDL in the UK.

Results The project began in 2008. The author is an epidemiologist/public health specialist so, analysed UK data, with guidance from experts from New Zealand, to determine whether young drivers crashed in circumstances reasonably covered by GDL. These data, along with evidence from Cochrane reviews and primary research, were then used in presentations to raise the profile of GDL. Efforts were made to present the evidence and data as widely as possible and to engage with politicians, policy makers, policy enforcers, the media and members of the general public. Understanding political drivers, both directly and indirectly related to road safety, has been vital. It has also been important to work, and develop strong links, with other academic sectors, mainly psychology, as well as the voluntary sector. Efforts have also been made to regularly update the evidence and reanalyse the data.

Conclusions There is no simple "how to" guide to public health advocacy, nor a quick way to get things done. GDL has not yet been implemented in the UK; but it is being more widely discussed and has a higher profile than at any time previously. Advocacy takes a very long time.

\section{TRANSLATING TO PRIMARY CARE PHYSICIANS AN EFFECTIVE SAFETY PROGRAM FOR PARENTS OF YOUNG DRIVERS}

${ }^{1}$ Jean Shope, ${ }^{1}$ Jennifer Zakrajsek, ${ }^{2}$ Stacia Finch, 'Raymond Bingham, ${ }^{3}$ Joseph O'Neil, ${ }^{4}$ Stephen Yano, ${ }^{2,5}$ Richard Wasserman, ${ }^{6}$ Bruce Simons-Morton. 'University of Michigan, USA; ${ }^{2}$ American Academy of Paediatrics, USA; ${ }^{3}$ Riley Hospital for Children, USA; ${ }^{4}$ Childrens' Medical Associates, Inc., USA; ${ }^{5}$ University of Vermont, USA; ${ }^{6}$ National Institutes of Health, USA

\subsection{6/injuryprev-2016-042156.328}

Background Crashes among US novice young drivers remain too high. Addressing this problem, one effective program for parents is Checkpoints, which raises parents' awareness of risks to their young drivers and offers ways to reduce those risks. But its most effective approach was in driver education classrooms and not widely available. A federally-funded study adapted Checkpoints to a website that could be promoted in several ways. This study promoted the Checkpoints website in brief interventions by Primary Care Practitioners (PCPs), and examined dissemination to/ implementation by parents.

Methods The website, youngdriverparenting.org (with an interactive parent-teen driving agreement, PTDA), and brief intervention protocol were developed in collaboration with leadership of Paediatric Research in Office Settings at the American Academy of Paediatrics. PCPs delivered interventions and materials to parents, referred them to the website, and completed follow-up surveys. Google Analytics was used to assess parents' website use. Results Focus groups of parents/teens determined the website adaptation successful. Most of the 133 PCPs from 16 states reported delivering interventions with fidelity, and thought the program important and feasible. Brief interventions/website referrals, averaging 4.4 minutes, were delivered to 3,465 (87\%) of 3,990 eligible parents over an 18-week average in 2012-2013. Website visits $(1,453)$ were made by $42 \%$ of parents exposed to the intervention, who spent on average 3.53 minutes viewing an average of 4.2 pages. The PTDA was viewed by $24 \%$, and $10 \%$ registered for an interactive PTDA.

Conclusions Translation of an evidence-based parent program to a PCP-promoted website was demonstrated. Delivering the brief intervention/website referral was feasible and acceptable to PCPs. This program costs little (its website, training and promotional materials are available) and could be one component of a comprehensive approach to reducing young driver crashes.

\section{A RANDOMISED TRIAL TO IMPROVE NOVICE DRIVING}

${ }^{1}$ Corinne Peek-Asa, ${ }^{1}$ Cara Hamann, ${ }^{2}$ Michelle Reyes, ${ }^{2}$ Dan McGehee. ${ }^{1}$ University of lowa Injury Prevention Research Centre, USA; ' University of lowa Public Policy Centre, USA

\subsection{6/injuryprev-2016-042156.329}

Background Motor vehicle crashes are a leading cause of death worldwide, and novice drivers have the highest crash risk. Interventions that integrate parents in motivating safe teen driving are a promising strategy.

Methods A randomised trial tested two intervention strategies: in-vehicle video feedback and a parent-focused communication program called "Steering Teens Safe (STS)." For the in-vehicle video feedback, two small video cameras with GPS recorded driving and driving errors (exceeding a threshold for acceleration/ deceleration or lateral movement). A blinking light alerted drivers of an error, and parents received a weekly report card with video clips and a summary. STS trained parents to improve the quality 
and quantity of parent-teen communication about safe driving. Evaluations have shown both interventions to be effective independently, but no studies have examined parent-teen interaction related to in-vehicle feedback systems. 153 parent-teen dyads were recruited through local high schools and randomised to one of three groups: control; in-vehicle video feedback; and feedback with STS.

Preliminary Results During baseline (4 weeks), groups averaged between 22 and 27 driving errors per week. The STS plus video group reduced their average driving errors to 8 in the first month (a 64\% reduction) and to five or less in the second through fourth months $(-77 \%)$. The video only group had a slight reduction of 27 to $23(-15 \%)$ driving errors in the first month, then reduced to ten or less for months two through four $(-63 \%)$. The control group did not show any decrease in driving errors. Proportionate hazards models indicate that the STS group had a significantly faster reduction in driving errors, and both intervention groups had significant reductions by the fourth month.

Conclusions In-vehicle video feedback systems effectively reduce driving errors, and the effectiveness is significantly improved when paired with a parent-focused communication program.

\section{YOUNG DRIVER CRASH TYPES AND LIFETIME CARE COSTS BY POSTED SPEED LIMIT}

${ }^{1}$ Samantha Buckis, ${ }^{1}$ Mike G Lenné, ${ }^{1}$ Amanda Stephens, ${ }^{2} \mathrm{C}$ Raymond Bingham and ${ }^{1}$ Michael Fitzharris. 'Accident Research Centre, Monash University, Melbourne, Australia; ${ }^{2}$ UMTRI, University of Michigan, Ann Arbour, USA

\subsection{6/injuryprev-2016-042156.330}

Background Speeding is a key issue for all drivers as it influences both crash risk and crash severity. Young drivers, particularly males, are more likely to engage in speeding behaviour and speeding is a common contributing factor in young driver crashes. Greater understanding of the impact of speed and speeding on young driver crash risk and crash outcomes is required to inform the development, prioritisation and implementation of evidence-based safety interventions.

Methods In Victoria, Australia, the Transport Accident Commission (TAC) operates as the sole, statutory compensation $\left(3^{\text {rd }}\right.$ party insurance) scheme. The TAC has legislated responsibility for road safety and the care of persons injured in road crashes, irrespective of fault. TAC claims data for the period 2005-2013 was used to analyse the differences in crash types and injury outcomes, including cost, by posted speed limit (30, 40, 50, 60, 70, $75,80,90,100$ and $110 \mathrm{~km} / \mathrm{h})$. The mean and overall lifetime care costs were analysed by speed limit. Speed limit was also analysed by age, gender, location, time of day and crash type. Young drivers were split into two groups for comparison 18-21 and 2225.

Results Over the 9-year period, 16,794 claims were lodged to the TAC for killed or injured drivers 18-25 years of age (young drivers). The total lifetime care cost for all young drivers killed or injured in a crash was estimated to be \$AUD634 million. The total lifetime care cost for young male drivers was estimated to be \$AUD470 million compared to \$AUD163 million for young female drivers. 18 to 21 year old drivers accounted for \$AUD356 million compared to \$AUD279 million for 22 to 25 year old drivers. When the posted speed limit is considered, the total cost of killed or injured young drivers who crashed in $60 \mathrm{~km} / \mathrm{h}$ zones $(\mathrm{N}=3914)$ was estimated to be \$AUD70 million $(M=$ \$AUD
17,807), compared to \$AUD208 million ( $M=$ \$AUD 65,580$)$ in $100 \mathrm{~km} / \mathrm{h}$ zones $(\mathrm{N}=3173)$.

Conclusions Road trauma not only has an enormous impact on the lives of those involved, their families and friends, it also has a significant economic burden on our communities. This research demonstrates that speed and male gender play key roles in crash outcomes, particularly lifetime care costs, and should be essential considerations for safety interventions.

\section{WHY RESEARCH IS INDISPENSABLE TO SMART PUBLIC POLICY}

Anthony Green. Safe Kids Worldwide

\subsection{6/injuryprev-2016-042156.331}

Background Laws are essential in all efforts to save young lives. It is important to reinforce the indispensable role evidence plays in winning an advocacy effort, just as evidence is the foundation for all aspects of public safety campaigns, messaging and education.

Description of the problem In 2013, 2,163 kids 16-19 were killed in U.S. car crashes. Drivers aged 16-19 are nearly three times more likely to be in a fatal car crash than those aged 20 and older. The risk is greater because teens are less likely to recognise road dangers than older drivers and more likely to exceed speed limits. Of kids 13-20 dying in motor vehicle crashes, only $56 \%$ were wearing seat belts.

Results There is a body of evidence that stronger Graduated Driver License (GDL) laws save lives as demonstrated in the U.S., and also in Canada, Sweden and New Zealand. Since Illinois passed a tougher GDL law there's been a 57\% reduction in teen motor crashes. Connecticut has one of the most stringent GDL laws in the U.S., and in 2014, not a single 16- or 17- year old passenger was killed in a crash involving a driver in the same age group. In addition, evidence based online applications can predict how many lives are saved through various GDL interventions. As an example, a "calculator" created by the respected Insurance Institute for Highway Safety predicts that if Arkansas raised its permit age to 16 and limited night driving, there could be a $26 \%$ reduction in fatal crashes. Safe Kids has cited the calculator in a successful advocacy effort in the U.S. Senate and it was used in an effort in New Jersey. The combination of real time data and modelling tools from a credible research organisation are powerful weapons to influence child safety policy change.

Conclusions Advocacy campaigns require a foundation of data and evidence, and the research function should be part of the planning process in developing a campaign.

\section{INNOVATIVE STRATEGIES TO REDUCE TRAFFIC RELATED INJURIES AND DEATHS IN YOUTH}

${ }^{1}$ Joanne Banfield, ${ }^{2}$ Donald Redelmeier. 'Sunnybrook Health Sciences Centre, Canada; ${ }^{2}$ University of Toronto, Canada

\subsection{6/injuryprev-2016-042156.332}

Background Road traffic injuries are the leading cause of death among young people, aged 15-29 years. Studies have shown young drivers are more likely to underestimate the probability of specific risks caused by traffic situations, as well as to overestimate their own driving skills making them more vulnerable to trauma. The P.A.R.T.Y. (Prevent Alcohol and Risk-Related Trauma 